\title{
ANTIMICROBIAL POTENTIAL OF HERBAL AND CHEMICAL NEONATAL EYE DROPS
}

\author{
NITIKA THAKUR*, JYOTI KUMARI, MONU SHARMA
}

Department of Biotechnology, Shoolini University, Bajhol Campus, Solan, Himachal Pradesh, India. Email: nitikathakur45@gmail.com Received: 21 June 2018, Revised and Accepted: 16 July 2018

\begin{abstract}
Objective: The present study focuses on exploring the antimicrobial potential of chemical (Tobastar and natamycin) and herbal eye drops (Itone) which are specifically preferred against neonatal eye infections.
\end{abstract}

Methods: Well diffusion method (for testing the antimicrobial potential of selected eye drops against different bacterial and fungal strains), minimum inhibitory concentration (MIC) (broth dilution method) for detecting the MIC effective against various strains taken into consideration.

Results: The results indicated that Itone and Tobastar are effective against bacterial strains, thus highlighting the importance of these two eye drops against bacterial infections, whereas natamycin is effective against fungal infection.

Conclusion: It may be concluded that the herbal eye drop (Itone) and the chemical eye drop (Tobastar) are effective against bacterial infections. The components such as neem, tulsi, kapur, and honey in herbal composition possess good antibacterial activity confirming the great potential of bioactive compounds and are useful for the growth inhibition of the carcinogenic bacterium. The alkaloids, flavonoids and saponins are based on antibiotic principles and are actually the defensive mechanisms of the plant against pathogens and chemical eye drop, that is, natamycin is effective against fungal infections, which may be due to the presence of polyene antifungal agent which works against fungal infections. There is a need to optimize the blending of the different herbal and chemical components to form a single effective antimicrobial formulation (more of herbal component and less chemical components) against neonatal infections.

Keywords: Neonatal, Eye infection, Antimicrobial, Herbal eye drops, Chemical eye drops, Formulations.

(C) 2018 The Authors. Published by Innovare Academic Sciences Pvt Ltd. This is an open access article under the CC BY license (http://creativecommons. org/licenses/by/4. 0/) DOI: http://dx.doi.org/10.22159/ajpcr.2018.v11i11.28026

\section{INTRODUCTION}

The human eye is a highly intricate and delicate organ with many different processes and components. Eyes with resolving power have come in 10 fundamentally different forms, and $96 \%$ of animal species possess a complex optical system [1]. The pigment molecules used in the eye are various but can be used to define the evolutionary distance between different groups and can also be an aid in determining which are closely related, although problems of convergence do exist (Goldsmith, 1990). The opsin protein group evolved long before the last common ancestor of animals and has continued to diversify till date (Francesca; Adriana, (2008). The studies also show that both artificial tears, $0.3 \%$ SH and HPMC/dextran, alleviate the signs and symptoms of dry eye disease, broken out in patients who have undergone PRK surgery [2]. In 2008, Rolando et al. reported about two different manifestations of brucellosis, and ophthalmologic and neuro-ophthalmologic types [3].

\section{Herbal eye drop}

Herbal eye drop keeps eye healthy, clean, and clear. It helps in improving eyesight, relieving itching, redness, burning, and watering in eyes [4]. The herbal eye drop formulation is prepared for beneficial effects in inflammatory and allergic conditions of the eyes. Itone eye drops are an unparalleled preparation made from the ancient Ayurveda, rediscovered through extensive in-house research. It is priceless in protecting the eyes from all pollutions and harmful surroundings of modern life [5].

\section{Chemical eye drop}

Eye drops usually have saline as base ingredients. They can keep the eyes wet and red out. Sometime they are medicine. The chemical eye drops are used for cataract surgery, contact lens rewetting, infected cornea, and corneal transplant surgery [6]. Natamycin, also known as pimaricin, is an antifungal medication used to treat fungal infections around the eye. This includes infections of the eyelids, conjunctiva, and cornea. It is used as eye drops. Natamycin was discovered in 1955 [7] and approved for medical use in the United States in 1978 [8].

\section{METHODS}

Survey report

The survey was conducted in the mid hills of Himachal Pradesh (Solan) for the specified eye drops, highly effective against various neonatal infections. The survey included a visit to many different chemist shops for selection of the best eye drops on the basis of people's preferences (Table 1) and pharmacist's analysis.

\section{Methodology}

The selected eye drops: Herbal (Itone) and chemical (Tobastar and natamycin) were labeled as A, B, and C. The herbal eye drop (Itone) was labeled as "A," the Tobastar eye drop was labeled as "B," whereas $\mathrm{C}$ was natamycin, respectively. Successively, dilutions of these eye drops were made at different concentrations in methanol. The concentration range was selected from 2 to $15 \mu \mathrm{L}$. Three different concentrations of each eye drop were prepared. The concentration of eye drop A that is $2 \mu \mathrm{L}, 4 \mu \mathrm{L}$, and $6 \mu \mathrm{L}$ was dissolved in $1 \mathrm{~mL}$ of methanol in Eppendorf and labeled as A1, $\mathrm{A} 2$, and $\mathrm{A} 3$, respectively. In A1, $2 \mu \mathrm{L}$ concentration of herbal eye drop was dissolved in $1 \mathrm{~mL}$ of methanol. In A2, $4 \mu \mathrm{L}$ concentration of the herbal eye drop was dissolved in $1 \mathrm{~mL}$ of methanol. In A3, $6 \mu \mathrm{L}$ concentration of the herbal eye drop was added in $1 \mathrm{~mL}$ of methanol. The eye drop B (chemical eye drop) named Tobastar was also labeled similarly as B1, B2, and B3. In $\mathrm{B} 1,2 \mu \mathrm{L}$ concentration of the Tobastar eye drop was dissolved in $1 \mathrm{ml}$ of methanol. In B2, $4 \mu \mathrm{L}$ Tobastar was dissolved in $1 \mathrm{~mL}$ of methanol. In B3, $6 \mu \mathrm{L}$ of Tobastar was dissolved successively in $1 \mathrm{~mL}$ of methanol, and the same procedure of dilutions was followed for eye drop C. The higher concentrations ( $5 \mu \mathrm{L}, 10 \mu \mathrm{L}$, and $15 \mu \mathrm{L})$ were additionally used, and the same procedure was followed as stated in lower dilutions [9]. 
Table 1: List of the selected eye drops (chemical and herbal) which are generally preferred against neonatal eye infections

\begin{tabular}{lllll}
\hline Serial number & Eye drops (chemical and herbal) & Shop no. 1 & Shop no. 2 & Shop no. 3 \\
\hline 1. & Herbal eye drop & Itone & Itone & Himalaya eye drop \\
2. & Chemical eye drop & Tobastar and natamycin & Vigamox and Tobastar & Tobastar and natamycin \\
\hline
\end{tabular}

Table 2: Zone of inhibition was measured against different bacterial strains at $15 \mu \mathrm{L}$ concentration

\begin{tabular}{llllll}
\hline Strains & Sample A & Sample B & Sample C & Streptomycin & Methanol \\
\hline E. coli & 12 & 19 & 6 & 28 & 6 \\
S. aureus & 6 & 20 & 6 & 28 & 6 \\
Listeria & 6 & 22 & 6 & 24 & 6 \\
\hline
\end{tabular}

Data represent mean \pm standard error of mean (n=6). SD: Standard deviation, E. coli: Escherichia coli, S. aureus: Staphylococcus aureus

Table 3: Zone of inhibition was measured against different bacterial strains at $10 \mu \mathrm{L}$ concentration

\begin{tabular}{lllllll}
\hline Strains & Sample A & Sample B & Sample C & Streptomycin & Methanol & Mean \pm SD \\
\hline E. coli & 10 & 20 & 6 & 26 & 6 & $12 \pm 7.211103$ \\
S. aureus & 6 & 20 & 6 & 27 & 6 & $10.66667 \pm 8.082904$ \\
Listeria & 6 & 23 & 6 & 28 & 6 & $11.66667 \pm 9.814955$ \\
\hline
\end{tabular}

SD: Standard deviation, E. coli: Escherichia coli, S. aureus: Staphylococcus aureus, Data represent mean \pm standard error of mean (n=6)

Table 4: Zone of inhibition was measured against different bacterial strains at $5 \mu \mathrm{L}$ concentration.

\begin{tabular}{llllll}
\hline Strains & Sample A & Sample B & Sample C & Streptomycin & Methanol \\
\hline E. coli & 11 & 18 & 6 & 21 & 6 \\
S. aureus & 6 & 21 & 6 & 23 & 6 \\
Listeria & 6 & 22 & 6 & 22 & $11.66667 \pm 6.21114$ \\
\hline
\end{tabular}

Data represent mean \pm standard error of mean $(\mathrm{n}=6)$. SD: Standard deviation, E. coli: Escherichia coli, S. aureus: Staphylococcus aureus

Table 5: Zone of inhibition was measured against $C$. albicans strain at $5 \mu \mathrm{L}, 10 \mu \mathrm{L}$, and $15 \mu \mathrm{L}$ concentration

\begin{tabular}{lllllll}
\hline Dilutions & Sample A & Sample B & Sample C & Fluconazol & Methanol & Mean \pm SD \\
\hline $5 \mu \mathrm{L}$ & 6 & 6 & 38 & 26 & 6 & $16.66667 \pm 18.47521$ \\
$10 \mu \mathrm{L}$ & 6 & 6 & 37 & 27 & 6 & $16.33333 \pm 17.89786$ \\
$15 \mu \mathrm{L}$ & 6 & 6 & 36 & 28 & 6 & $16 \pm 17.32051$ \\
\hline
\end{tabular}

Data represent mean \pm standard error of mean (n=6). SD: Standard deviation, E. coli: Escherichia coli, S. aureus: Staphylococcus aureus

Table 6: MIC was found to be $0.5 \mu \mathrm{L} / \mathrm{mL}$ at $10 \mu \mathrm{L}$ (A eye drop), $0.125 \mu \mathrm{L} / \mathrm{mL}$ at $5 \mu \mathrm{L}$ (B eye drop), and $0.75 \mu \mathrm{L} / \mathrm{mL}$ at $15 \mu \mathrm{L}$ (C eye drop)

\begin{tabular}{lllll}
\hline Results of MIC & \multicolumn{5}{l}{} \\
\hline Dilutions & E. coli & S. aureus & Listeria monocytogenes & C. albicans \\
\hline $10 \mu \mathrm{L}$ & $0.5 \mu \mathrm{L} / \mathrm{mL}$ & $0.5 \mu \mathrm{L} / \mathrm{mL}$ & $0.5 \mu \mathrm{L} / \mathrm{mL}$ & $0.5 \mu \mathrm{L} / \mathrm{mL}$ \\
$5 \mu \mathrm{L}$ & $0.125 \mu \mathrm{L} / \mathrm{mL}$ & $0.125 \mu \mathrm{L} / \mathrm{mL}$ & $0.125 \mu \mathrm{L} / \mathrm{mL}$ & $0.5 \mu \mathrm{L} / \mathrm{mL}$ \\
$15 \mu \mathrm{L}$ & $0.75 \mu \mathrm{LL}$ & $0.75 \mu \mathrm{LL}$ & $0.75 \mu \mathrm{LL} / \mathrm{mL}$ & $0.375 \mu \mathrm{L} / \mathrm{mL}$ \\
\hline
\end{tabular}

MIC: Minimum inhibitory concentration, E. coli: Escherichia coli, S. aureus: Staphylococcus aureus, C. albicans: Candida albicans

\section{Well diffusion test}

Well diffusion is a test of antibiotic sensitivity of bacteria and fungus. It uses antibiotic disc or antibiotic solution in well to test the extent to which bacteria and fungus are affected by these antibiotics [10]. The well diffusion method is simple and is well standardized; the test was performed by applying bacterial and fungal inoculum on bacterial and fungal culture by sterile cotton swab. Inoculum was spread over the entire surface of Nutrient agar and Potato dextrose agar plate. Antibiotics eye drops sample A, B, and C was fixed in the concentrations of $2 \mu \mathrm{L}, 4$ $\mu \mathrm{L}, 6 \mu \mathrm{L}, 5 \mu \mathrm{L}, 10 \mu \mathrm{L}$, and $15 \mu \mathrm{L}$ and also the positive (antibiotic disc) and negative control (methanol) Tables 2-4. These were allowed to dry for at least $15 \mathrm{~min}$ and then wells were made using sterile cork borer. About $25 \mu \mathrm{L}$ extract was introduced into agar wells using sterile dropping pipette. These plates were kept inside the refrigerator at $4^{\circ} \mathrm{C}$ for $6 \mathrm{~h}$ to allow proper diffusion of dilutions into medium. These plates of bacteria were incubated at $37^{\circ} \mathrm{C}$ for $24 \mathrm{~h}$ and fungal plates were incubated at $25^{\circ} \mathrm{C}$ for $48 \mathrm{~h}$ for the determination of result. The zones of inhibition around each well were measured to the nearest millimeter. The results of disc diffusion test were qualitative estimated by minimum inhibitory concentration (MIC 1). The agar plate is inoculated with a suspension of bacterial and fungus to be tested by putting the eye drop sample in the agar well, simultaneously growth of bacteria and fungus of the antimicrobial compound occurs [11].

MIC for the determination of antimicrobial activity of eye drop Each well of 96-well microtiter plates was filled with $100 \mu \mathrm{L}$ yeast extract peptone dextrose and nutrient broth; $12^{\text {th }}$ well (sterility control) was added with $100 \mu \mathrm{L}$ of chloramphenicol and amphotericin B antibiotic solution as positive control. In the $11^{\text {th }}$ well (growth well), $100 \mu \mathrm{L}$ of methanol was added as negative control. $50 \mu \mathrm{L}$ of dilution dissolved in methanol to the concentration of $100 \mathrm{mg} / \mathrm{mL}$ was added into the first well and a 2-fold serial dilution was performed by transferring $100 \mathrm{uL}$ of the suspension to the subsequent well up till to $10^{\text {th }}$ well; the final $100 \mathrm{uL}$ of the suspensions was discarded. Then, $10 \mathrm{uL}$ of bacterial and 
fungal culture was added to each well and incubated for $24 \mathrm{~h}$ at $37^{\circ} \mathrm{C}$ for bacteria fungal plate at $25^{\circ} \mathrm{C}$ at $48 \mathrm{~h}$. After incubation, $5 \mathrm{uL}$ of resazurin was added to each well. Plates were incubated at $37^{\circ} \mathrm{C}$ and $25^{\circ} \mathrm{C}$ for $1 \mathrm{~h}$. After $1 \mathrm{~h}$ of incubation, the plates were read for color change from blue to purple/pink. A blue color solution indicated the growth inhibition in the test wells, while pink to colorless solution indicated microbial growth or absence of inhibition (Weigand, 2008).

\section{RESULTS}

Result of $2 \mu \mathrm{L}, 4 \mu \mathrm{L}$, and $6 \mu \mathrm{L}$ dilution for antimicrobial potential The lower dilutions which ranged from $2 \mu \mathrm{L}, 4 \mu \mathrm{L}$, and $6 \mu \mathrm{L}$ were found effective against the bacterial and fungal strains. It was observed that in Escherichia coli, B eye drop (Tobastar) shows minimum zone of inhibition at $4 \mu \mathrm{L}$ concentration. Other two eye drops were not showing any zone of inhibition against it (Fig. 1). In Listeria, only B (Tobastar) eye drop has shown the zone of inhibition at $4 \mu \mathrm{L}$ concentration. The other two eye drops were not showing any zone of inhibition (Fig. 2). In Staphylococcus aureus, no zone of inhibition was observed (Fig. 4). For the fungal strain, Candida albicans, C eye drop (natamycin) shows the maximum zone of inhibition at $6 \mu \mathrm{L}$ concentration as compared to $\mathrm{A}$ $(2 \mu \mathrm{L})$ and $\mathrm{B}(4 \mu \mathrm{L})$ eye drop Fig. 3 . Whereas, the $\mathrm{C}$ (natamycin) eye drop shows the antifungal effect at $6 \mu \mathrm{L}$ concentration (Fig. 1)

Graphical representation of zone of inhibition was measured for different eye drops against E. coli, Listeria, and S. aureus, and Listeria

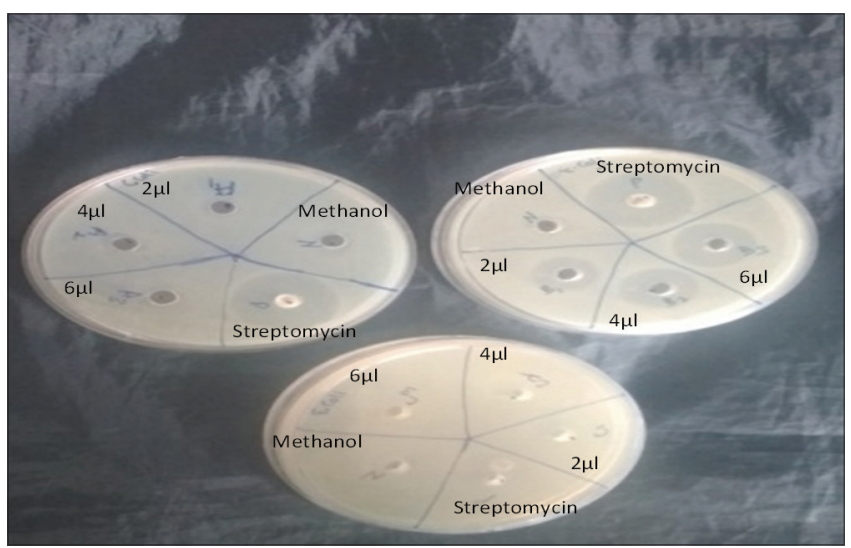

Fig. 1: Zone of inhibition was measured for different eye drops against Escherichia coli at different concentrations ranging from A (Itone) A1 $(2 \mu \mathrm{L}), \mathrm{A} 2(4 \mu \mathrm{L}), \mathrm{A} 3(6 \mu \mathrm{L}) ; \mathrm{B}$ (Tobastar) B1 $(2 \mu \mathrm{L})$, B2 $(4 \mu \mathrm{L}), \mathrm{B} 3(6 \mu \mathrm{L})$; and C (natamycin) C1 (2 $\mu \mathrm{L}), \mathrm{C} 2(4 \mu \mathrm{L})$, C3 $(6 \mu \mathrm{L})$, positive control (streptomycin disc), and negative control (methanol)

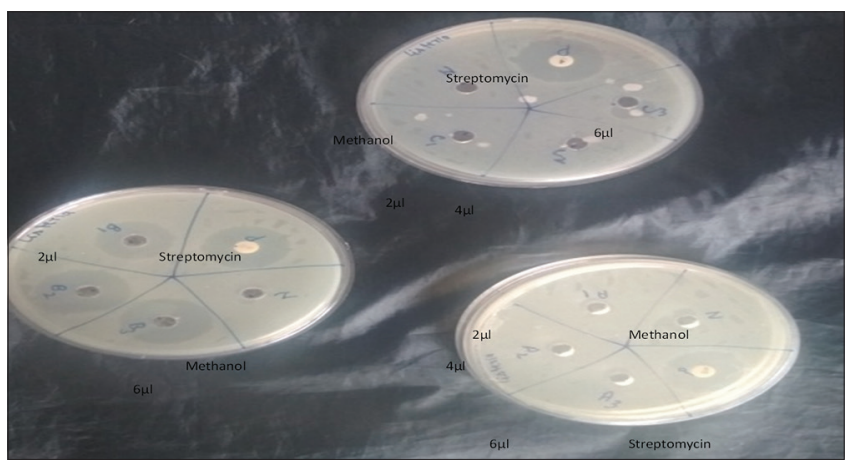

Fig. 2: Zone of inhibition was measured for different eye drops against Listeria at different concentrations ranging from $\mathrm{A}$ (Itone) A1 $(2 \mu \mathrm{L}), \mathrm{A} 2(4 \mu \mathrm{L}), \mathrm{A} 3(6 \mu \mathrm{L})$; B (Tobastar) B1 $(2 \mu \mathrm{L}), \mathrm{B} 2(4 \mu \mathrm{L})$, B3 $(6 \mu \mathrm{L})$; and C (natamycin) C1 $(2 \mu \mathrm{L}), \mathrm{C} 2(4 \mu \mathrm{L}), \mathrm{C} 3(6 \mu \mathrm{L})$, positive control (streptomycin disc), and negative control (methanol) at different concentrations ranging from $\mathrm{A}$ (Itone) $\mathrm{A} 1(2 \mu \mathrm{L}), \mathrm{A} 2(4 \mu \mathrm{L})$, A3 $(6 \mu \mathrm{L}) ; \mathrm{B}($ Tobastar) B1 $(2 \mu \mathrm{L}), \mathrm{B} 2(4 \mu \mathrm{L}), \mathrm{B} 3(6 \mu \mathrm{L})$; and C (natamycin) $\mathrm{C} 1(2 \mu \mathrm{L}), \mathrm{C} 2(4 \mu \mathrm{L}), \mathrm{C} 3(6 \mu \mathrm{L})$, positive control (streptomycin disc), and negative control (methanol) as shown in Figs. 5-7.

Results of $5 \mu \mathrm{L}, 10 \mu \mathrm{L}$, and $15 \mu \mathrm{L}$ dilution for antimicrobial potential With increasing concentration from 2 to $15 \mu \mathrm{L}$, in E. coli, B eye drop showed maximum zone of inhibition at $10 \mu \mathrm{L}$ concentration and herbal eye drop A shows zone of inhibition at $5 \mu \mathrm{L}$ concentration. Remaining eye drop was not showing any zone of inhibition (Fig. 8). In Listeria, only B (Tobastar) eye drop shows the zone of inhibition at $10 \mu \mathrm{L}$ concentration. The other two eye drops were not showing any zone of inhibition (Fig. 9). In S. aureus, B (Tobastar) eye drop shows some zone of inhibition against $S$. aureus at $10 \mu \mathrm{L}$ concentration (Fig. 10). For fungal strain, C. albicans, C eye drop (natamycin) shows the maximum zone of inhibition at $15 \mu \mathrm{L}$ concentration as compare to A and B eye drop at 5 $\mu \mathrm{L}$ and $10 \mu \mathrm{L}$ concentration Table 5 . C eye drop showed the antifungal effect at $15 \mu \mathrm{L}$ concentration (Fig. 11). Graphical representation shows

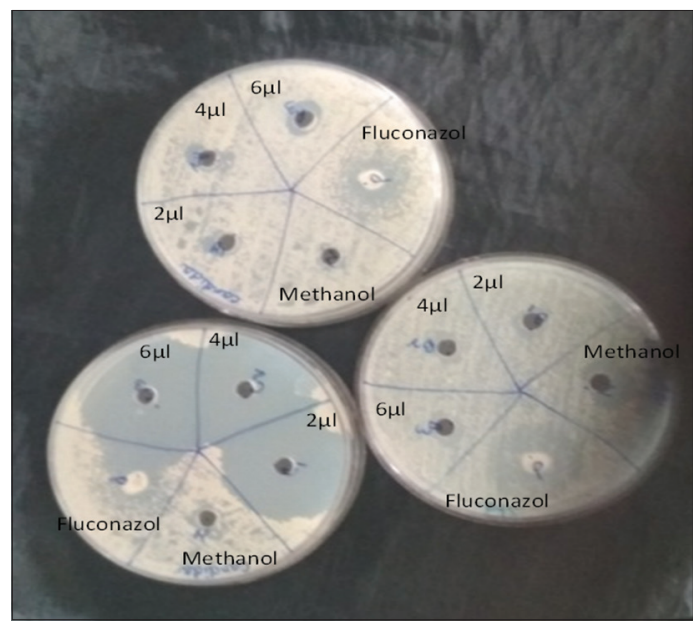

Fig. 3: Zone of inhibition was measured for different eye drops against Candida at different concentrations ranging from $\mathrm{A}$ (Itone) A1 (2 $\mu \mathrm{L}), \mathrm{A} 2(4 \mu \mathrm{L}), \mathrm{A} 3(6 \mu \mathrm{L}) ; \mathrm{B}$ (Tobastar) B1 (2 $\mu \mathrm{L})$ B2 $(4 \mu \mathrm{L}), \mathrm{B} 3(6 \mu \mathrm{L}) ;$ and C (natamycin) C1 $(2 \mu \mathrm{L}), \mathrm{C} 2(4 \mu \mathrm{L})$, C3 $(6 \mu \mathrm{L})$, positive control (fluconazole disc), and negative control (methanol)

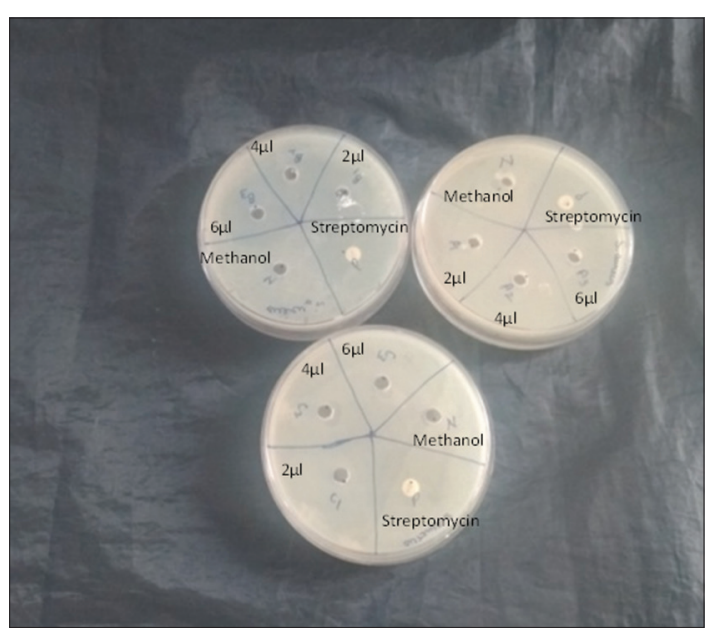

Fig. 4: Zone of inhibition was measured for different eye drops against Staphylococcus aureus at different concentrations ranging from A (Itone) A1 ( $2 \mu \mathrm{L}), \mathrm{A} 2(4 \mu \mathrm{L}), \mathrm{A} 3(6 \mu \mathrm{L}) ; \mathrm{B}$ (Tobastar) B1 $(2 \mu \mathrm{L}), \mathrm{B} 2(4 \mu \mathrm{L}), \mathrm{B} 3(6 \mu \mathrm{L}) ;$ and C (natamycin) C1 (2 $\mu \mathrm{L})$, C2 $(4 \mu \mathrm{L}), \mathrm{C} 3(6 \mu \mathrm{L})$, positive control (streptomycin disc), and negative control (methanol) 


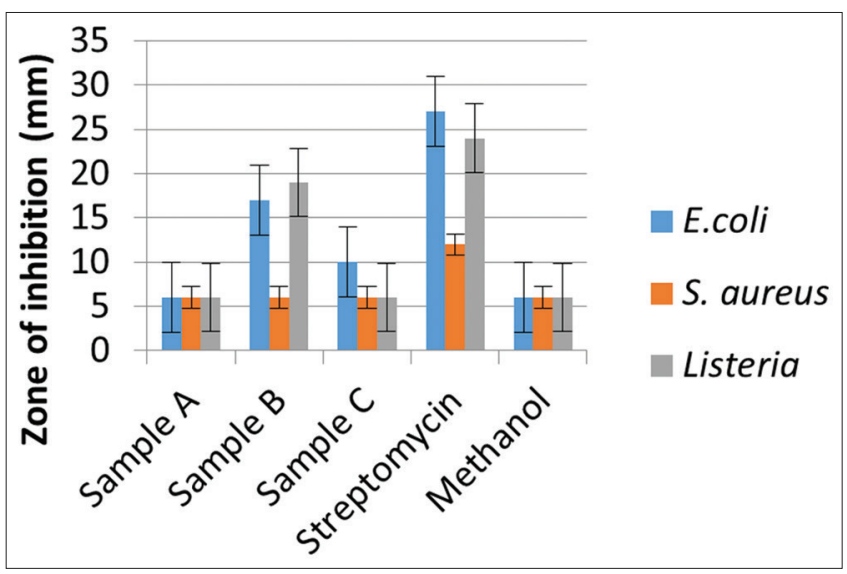

Fig. 5: For $2 \mu \mathrm{L}$ concentration

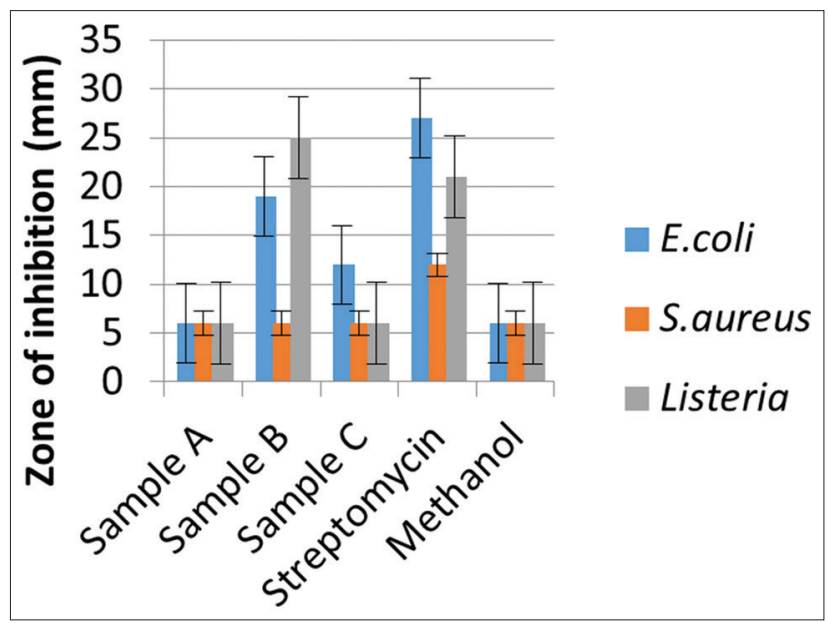

Fig. 6: For $4 \mu \mathrm{L}$ concentration

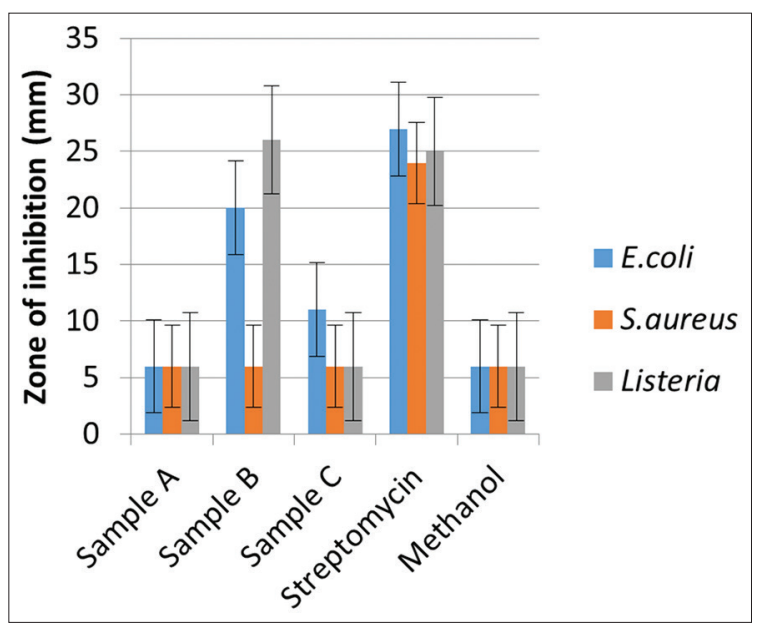

Fig. 7: For $6 \mu \mathrm{L}$ concentration

the zone of inhibition against bacterial and fungal strain at different concentrations of $5 \mu \mathrm{L}, 10 \mu \mathrm{L}$, and $15 \mu \mathrm{L}$.

It may be concluded that the herbal eye drop A (Itone) and chemical eye drop B (Tobastar) show antibacterial effect and chemical eye drop $C$ (natamycin) shows the antifungal effect.

MIC

MIC was performed by Broth dilution method. In this, different concentrations were taken and added into the 96-well microtiter plate.

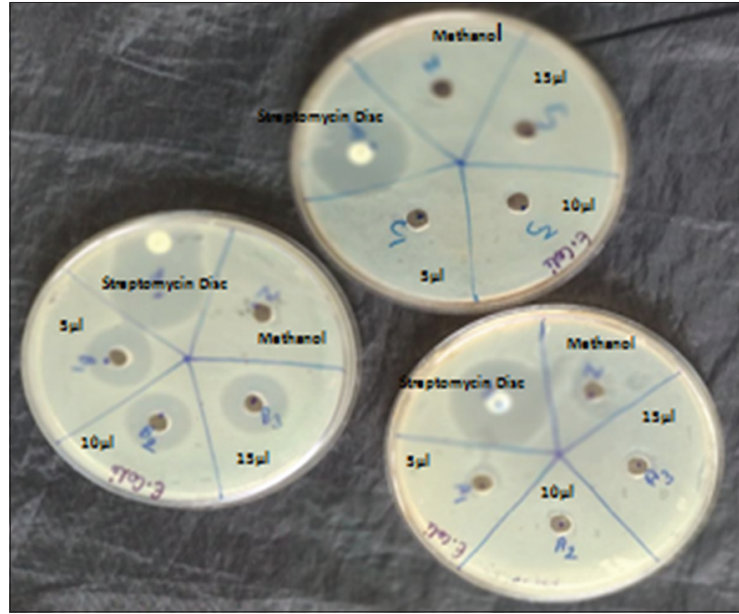

Fig. 8: Zone of inhibition was measured for different eye drops against Escherichia coli at different concentrations ranging from A (Itone) A1 (5 $\mu \mathrm{L}), \mathrm{A} 2(10 \mu \mathrm{L}), \mathrm{A} 3(15 \mu \mathrm{L}) ; \mathrm{B}$ (Tobastar) B1 (5 $\mu \mathrm{L})$, B2 $(10 \mu \mathrm{L}), \mathrm{B} 3(15 \mu \mathrm{L}) ;$ and C (natamycin) C1 $(5 \mu \mathrm{L}), \mathrm{C} 2(10 \mu \mathrm{L})$, C3 $(15 \mu \mathrm{L})$, positive control (streptomycin disc), and negative control (methanol)

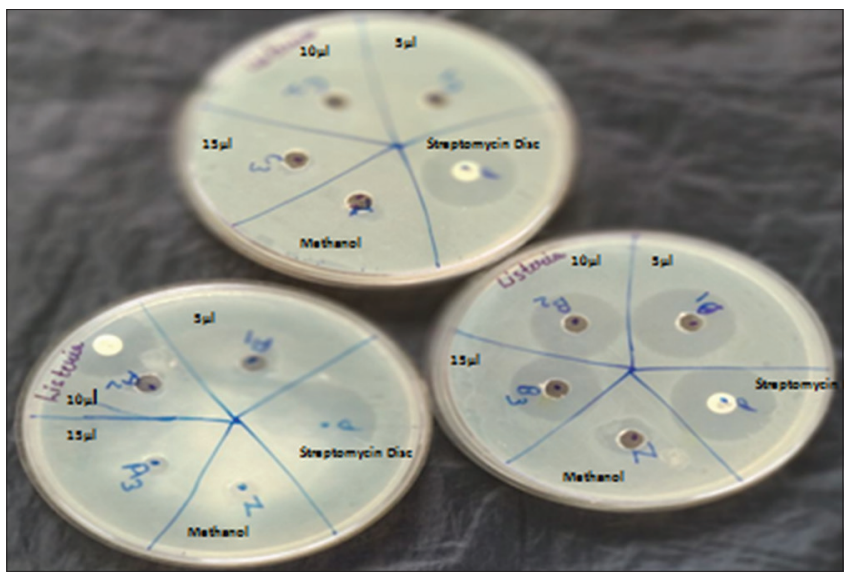

Fig. 9: Zone of inhibition was measured for different eye drops against Listeria at different concentrations ranging from $A$ (Itone) A1 (5 $\mu \mathrm{L}), A 2(10 \mu \mathrm{L}), A 3(15 \mu \mathrm{L}) ;$ B (Tobastar) B1 (5 $\mu \mathrm{L})$, B2 $(10 \mu \mathrm{L}), \mathrm{B} 3(15 \mu \mathrm{L}) ;$ and C (natamycin) C1 $(5 \mu \mathrm{L}), \mathrm{C} 2(10 \mu \mathrm{L})$, C3 $(15 \mu \mathrm{L})$, positive control (streptomycin disc), and negative control (methanol)

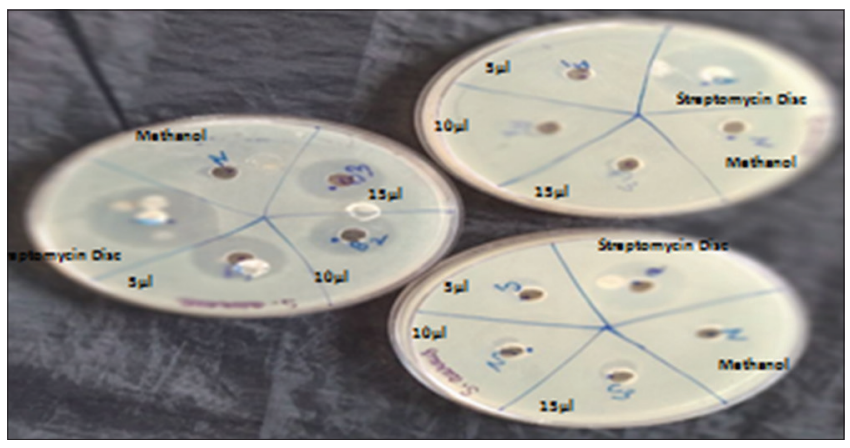

Fig. 10: Zone of inhibition was measured for different eye drops against Staphylococcus aureus at different concentrations ranging from A (I tone) A1 (5 $\mu \mathrm{L})$, A2 $(10 \mu \mathrm{L})$, A3 (15 $\mu \mathrm{L})$; B (Tobastar) B1 (5 $\mu \mathrm{L})$, B2 $(10 \mu \mathrm{L})$, B3 $(15 \mu \mathrm{L})$; and C (natamycin) C1 (5 $\mu \mathrm{L})$, C2 $(10 \mu \mathrm{L}), \mathrm{C} 3(15 \mu \mathrm{L})$, positive control (streptomycin disc), and negative control (methanol) 


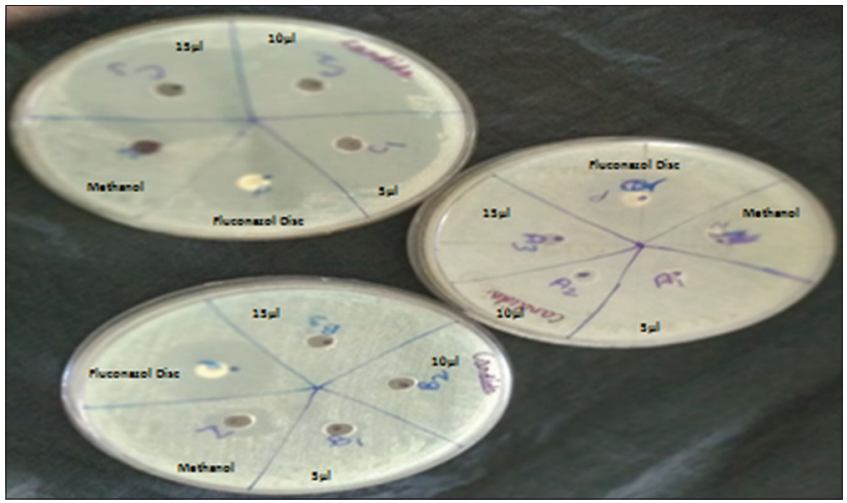

Fig. 11: Zone of inhibition was measured for different eye drops against Candida at different concentrations ranging from $\mathrm{A}$ (Itone) A1 (5 $\mu \mathrm{L}), A 2(10 \mu \mathrm{L}), \mathrm{A} 3(15 \mu \mathrm{L}) ; \mathrm{B}$ (Tobastar) B1 (5 $\mu \mathrm{L}), \mathrm{B} 2(10 \mu \mathrm{L})$,

B3 $(15 \mu \mathrm{L})$; and C (natamycin) C1 (5 $\mu \mathrm{L}), \mathrm{C} 2(10 \mu \mathrm{L}), \mathrm{C} 3(15 \mu \mathrm{L})$ positive control (fluconazole disc), and negative control (methanol)

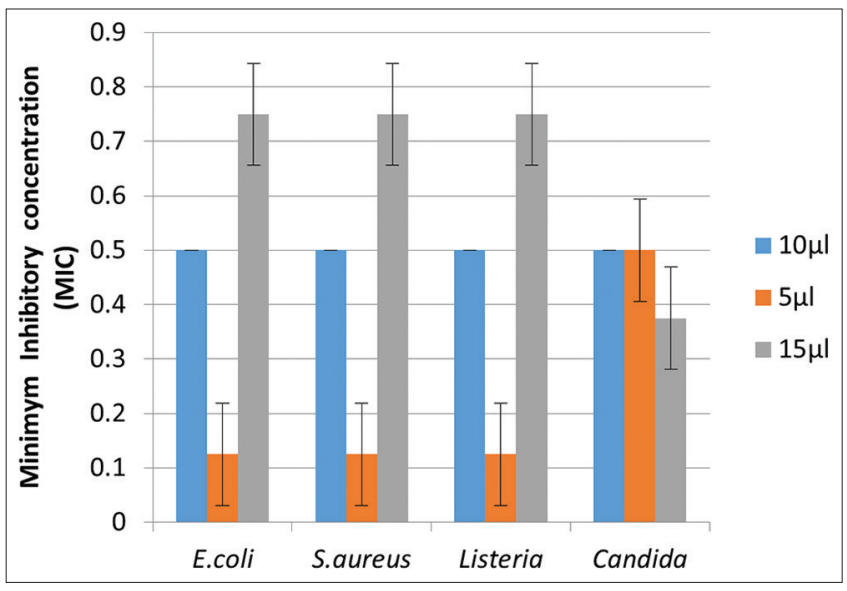

Fig. 12: Graphical representation of minimum inhibitory concentration against different strains (bacterial and fungal strain) at $10 \mu \mathrm{L}$ (A eye drop), $5 \mu \mathrm{L}$ (B eye drop), and $15 \mu \mathrm{L}$ (C eye drop) dilutions

In the end, resazurin dye was added into the plate to check the color change from blue to pink. Blue color indicates the microbial growth or absence of inhibition. Pink color indicates the growth inhibition in the test well Table 6.

\section{DISCUSSION}

The antimicrobial potential of neonatal eye drops was tested in the present study. It was observed that the maximum antifungal activity against C. albicans was shown by natamycin (C) at $5 \mu \mathrm{L}, 10 \mu \mathrm{L}$, and $15 \mu \mathrm{L}$ dilution. The present trend shown by natamycin may be attributed to the presence of polyene antifungal agent which works against fungal infection [12]. In this study, the antibacterial activity was shown by herbal eye drop (Itone) A and the (Tobastar) B eye drop against Listeria, E. coli, and S. aureus. The $B$ eye drop shows the antibacterial effect in all dilutions in all strains, due to the presence of aminoglycoside antibiotics that kill susceptible bacteria by blocking bacterial protein synthesis (FDA, 1980). The trend visualized in the present study may be attributed to many antibacterial agents having similar spectra of activity, as they are not equally potent against several organisms and may vary in their pharmacokinetic properties. The A eye drop (Itone) shows the antibacterial effect against $E$. coli, due to the presence of its components such as neem, tulsi, kapur, and honey. According to the researchers, these components possess good antibacterial activity confirming the great potential of bioactive compounds and are useful for the growth inhibition of the carcinogenic bacterium. The alkaloids, glycosides, flavonoids, and saponins are antibiotic principles and are actually the defensive mechanisms of the plant against pathogens [13].
Novelty of the research conducted

- The present studies are the pioneer studies to check the effectiveness of herbal preparations and chemical preparations against various bacterial and fungal agents. The main purpose was to check the antimicrobial potential of various formulations against different bacterial and fungal strains so that in future a combined formulation of antimicrobial agent $(80 \%$ herbal +20 chemical) can be standardized which can be safe for neonates and can potentially work against various neonatal eye infections.

\section{CONCLUSION}

The antimicrobial assay was performed (well diffusion assay) which focused on the antimicrobial activities of the selected eye drops. It may be concluded from the antimicrobial assay and MIC results that the herbal eye drop (Itone) and chemical eye drop were effective against bacterial infection, whereas natamycin holds good potential as antifungal agent [14]. There stands an urgent need for optimization process of both chemical and herbal eye drops so that an efficient and specific combined formulation can be made which is effective as one agent against both bacterial and fungal neonatal eye infection.

\section{AUTHORS' CONTRIBUTION}

Dr. Nitika Thakur (Assistant Professor, Microbiology) (First and the corresponding author) has designed and conducted the work keeping in view the importance of neonatal eye infections. The other authors (Jyoti and Monu Sharma) have performed the analysis part. The manuscript and statistical analysis was reframed by Dr. Nitika Thakur.

\section{COMPETING INTERESTS}

The authors declare that they have no competing interests.

\section{REFERENCES}

1. Land MF, Fernald RD. The evolution of eyes. Annu Rev Neurosci 1992;15:1-29.

2. Kasetsuwan N, Reinprayoon U. A sodium hyaluronate ophthalmic solution for reducing dry eye and enhancing corneal wound healing after photorefractive keratectomy. Asian J Pharm Clin Res 2015;8:226-31.

3. Sen A, Banerjee P, Dutta D, Pal M, Ray A, Das S. Brucellar uveitis in Eastern India. Asian J Pharm Clin Res 2016;9:196-200.

4. Arora R, Gupta D, Goyal J, Kaur R. Voriconazolo versus natamycin as primary treatment in fungal corneal ulcers. Clinical and Experiment Opthalmology 2011; 39 (5):434-440.

5. Ausubel FM, Brent R, Kingston RE, Moore DD, Seidman JG, Smith JA, et al. Current Protocols in Molecular Biology. Brooklyn, N.Y: Current Protocols; 1994.

6. Buranen L, Roy AM. Perspective on Plagiarism and Intellectual Property in a Postmodern World. Albany, NY: State University of New York Press; 1999.

7. Carson CF, Hammer KA, Riley TV. Broth micro-dilution method for determining the susceptibility of Escherichia coli and Staphylococcus aureus to the essential oil of Melaleuca alternifolia (tea tree oil). Microbios 1995;82:181-5.

8. Chand S, Lusunzi I, Veal DA, Williams LR, Karuso P. Rapid screening of the antimicrobial activity of extracts and natural products. J Antibiot (Tokyo) 1994;47:1295-304.

9. European Food Safety Authority (EFSA), Parma, Italy, European Centre For Disease Prevention and control (ECDC), Sweden. The European union summery reports on trends and sources of Zoonoses. Zoonotic agents and food born break in 2012. EFSA (European food safety system) J 2014;12:3547, 312.

10. Davidson PM, Parish ME. Method for testing the efficacy of food antimicrobial. Food Technol 1989;43:18-155.

11. Erdogan A, Rao SS. Small intestinal fungal overgrowth. Curr Gastroenterol Rep 2015;17:16.

12. Vandeputte P, Ferrari S, Coste AT. Antifungal resistance and new strategies to control fungal infection. Int J Microbiol 2012;2012:713687.

13. Sher A. Antimicrobial activity of natural product from medicinal plants. Gomel J Med Sci 2009; 7:72-8

14. Collins CH. Antibiotics and antibacterial substance. Microbiol Method 1994;296:305. 